\title{
Cricothyroidotomy incision length in female subjects - Are the Difficult Airway Society guidelines justified?
}

\section{P. Fennessy ${ }^{1}$, C. Mc Caul ${ }^{1}$ \\ ${ }^{1}$ Mater Misericordiae University Hospital - Dublin (Ireland)}

\section{Background and Goal of Study}

An $8-10 \mathrm{~cm}$ incision is recommended for vertical incision cricothyroidotomy when anatomy is indistinct as per the Difficult Airway Society Guidelines 2015. These guidelines are based on expert opinion. At present no evidence-based guideline exists regarding optimum site or length. We investigated clinician accuracy in identification of the cricothyroid membrane (CTM) of female patients.

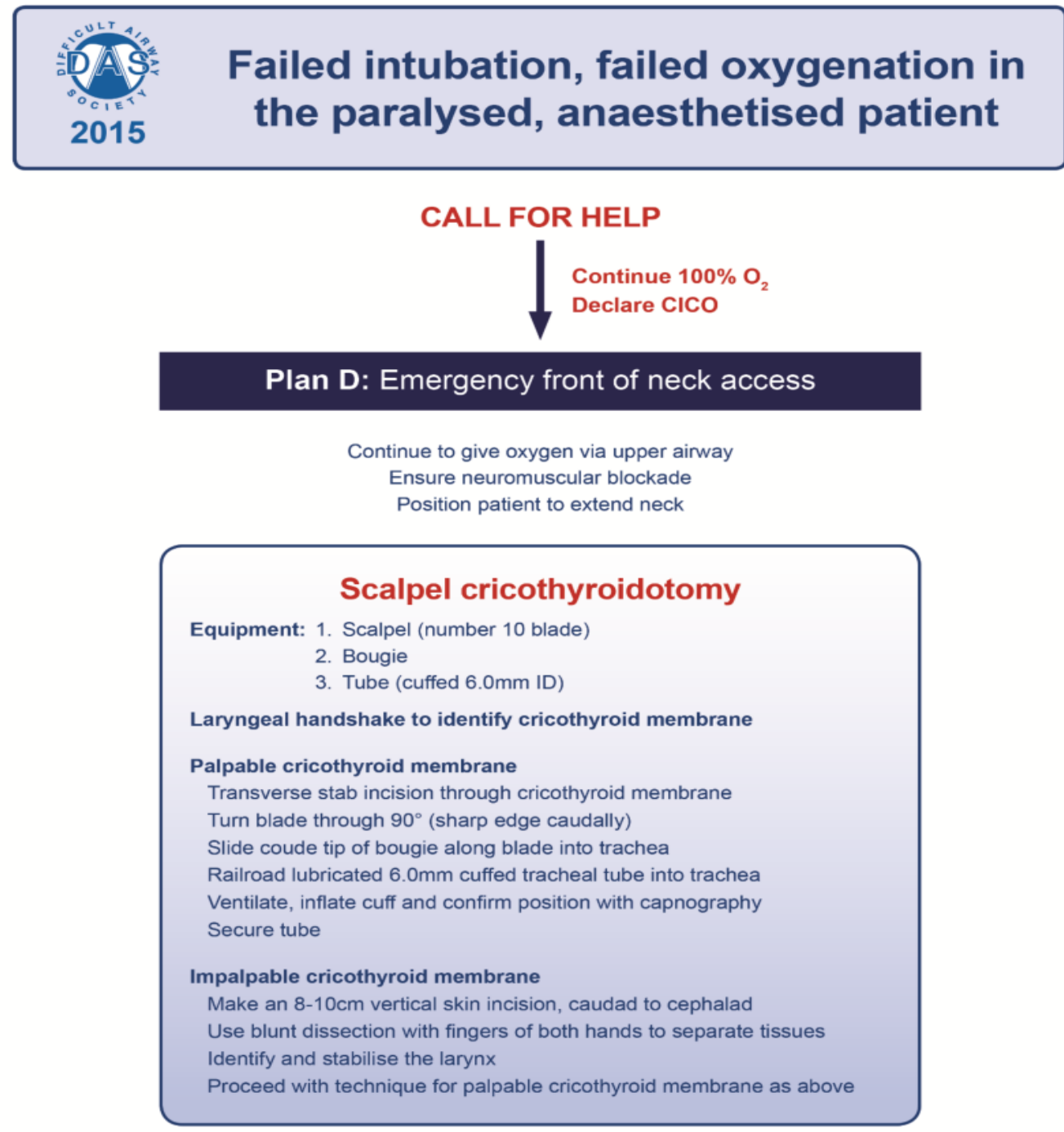

\section{Materials and Methods}

We asked clinicians to identify the CTM, in both the neutral and extended head positions. The distance between the actual (measured using ultrasound) and estimated location of the CTM was measured for both patient positions. We assessed 'capture' of the CTM within theoretical incisions of $0-10 \mathrm{~cm}$ in length using the best clinician estimate as the midpoint around which the incision would be performed. Our aim was to determine the optimum length of incision to capture all measured CTM locations.

\section{Neutral Position}

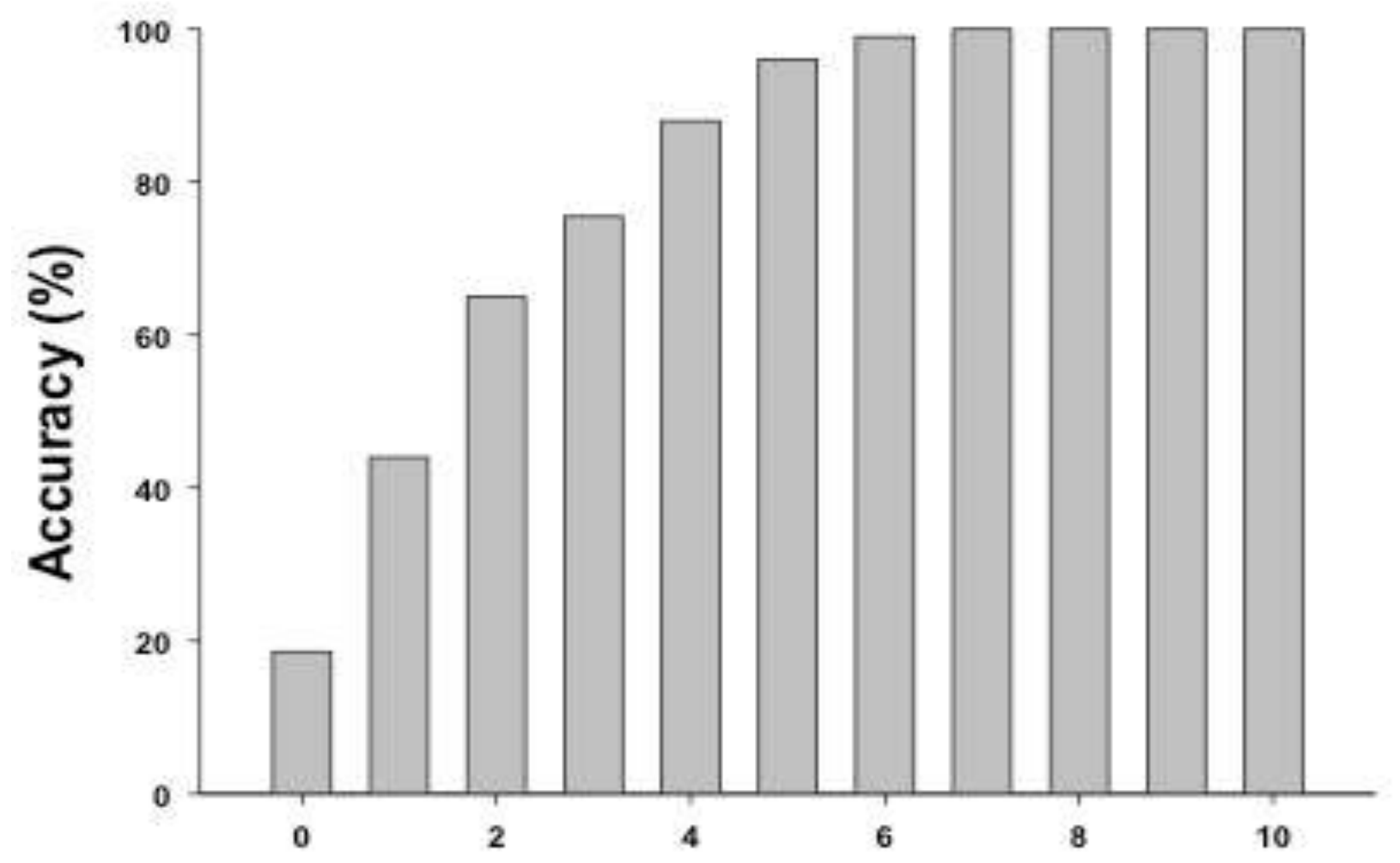

Hypothetical Incision Length

\section{Results and Discussion}

90 patients were recruited for this study. 66 patients were assessed in both the neutral and extended head position. A further 24 patients had 36 assessments in the neutral head position. In total 168 CTM assessments were performed. The CTM was correctly identified in $18 / 102(17.6 \%)$ neutral position assessments and $14 / 66(21.2 \%)$ of the extended position assessments. Clinician inaccuracy ranged from $3.2 \mathrm{~cm}$ above and $4 \mathrm{~cm}$ below the actual CTM location across both patient groups.

\begin{tabular}{lcc}
\hline & Neutral & Extended \\
\hline Total Assessments N & 102 & 66 \\
All Accuracy N (\%) & $18 / 102(17.6)$ & $14 / 66(21.2)$ \\
Consultant Assessments N (\%) & $22 / 102(21.6)$ & $11 / 66(16.7)$ \\
Consultant Accuracy N (\%) & $9 / 22(40.9)$ & $3 / 11(27.3)$ \\
Senior Trainee Assessments N (\%) & $63 / 102(61.8)$ & $49 / 66(74.2)$ \\
Senior Trainee Accuracy N (\%) & $7 / 63(11.1)$ & $9 / 49(18.4)$ \\
Junior Trainee Assessments N (\%) & $17 / 102(16.6)$ & $6 / 66(9.1)$ \\
Junior Trainee Accuracy N (\%) & $2 / 17(11.8)$ & $2 / 6(33.3)$ \\
Obese Accuracy N (\%) & $3 / 23(13.0)$ & $2 / 19(10.5)$ \\
Non-Obese Accuracy N (\%) & $15 / 79(18.9)$ & $12 / 47(25.5)$ \\
Above CTM N (\%) & $36 / 102(35.3)$ & $17 / 66(25.8)$ \\
Below CTM N (\%) & $47 / 102(46.1)$ & $34 / 66(51.5)$ \\
US-DP Distance (cm) & $1.17(-3.2$ to +2.8$)$ & $1.19(-4.0$ to \\
\hline
\end{tabular}

\section{Conclusion}

Using theoretical incisions of increasing length $(1 \mathrm{~cm}$ intervals), an incision size of $8 \mathrm{~cm}$ with the best clinician estimate as the midpoint would capture all CTM locations in both neutral and extended head positions. Our data thus supports the DAS guidelines.

\section{Extended Position}

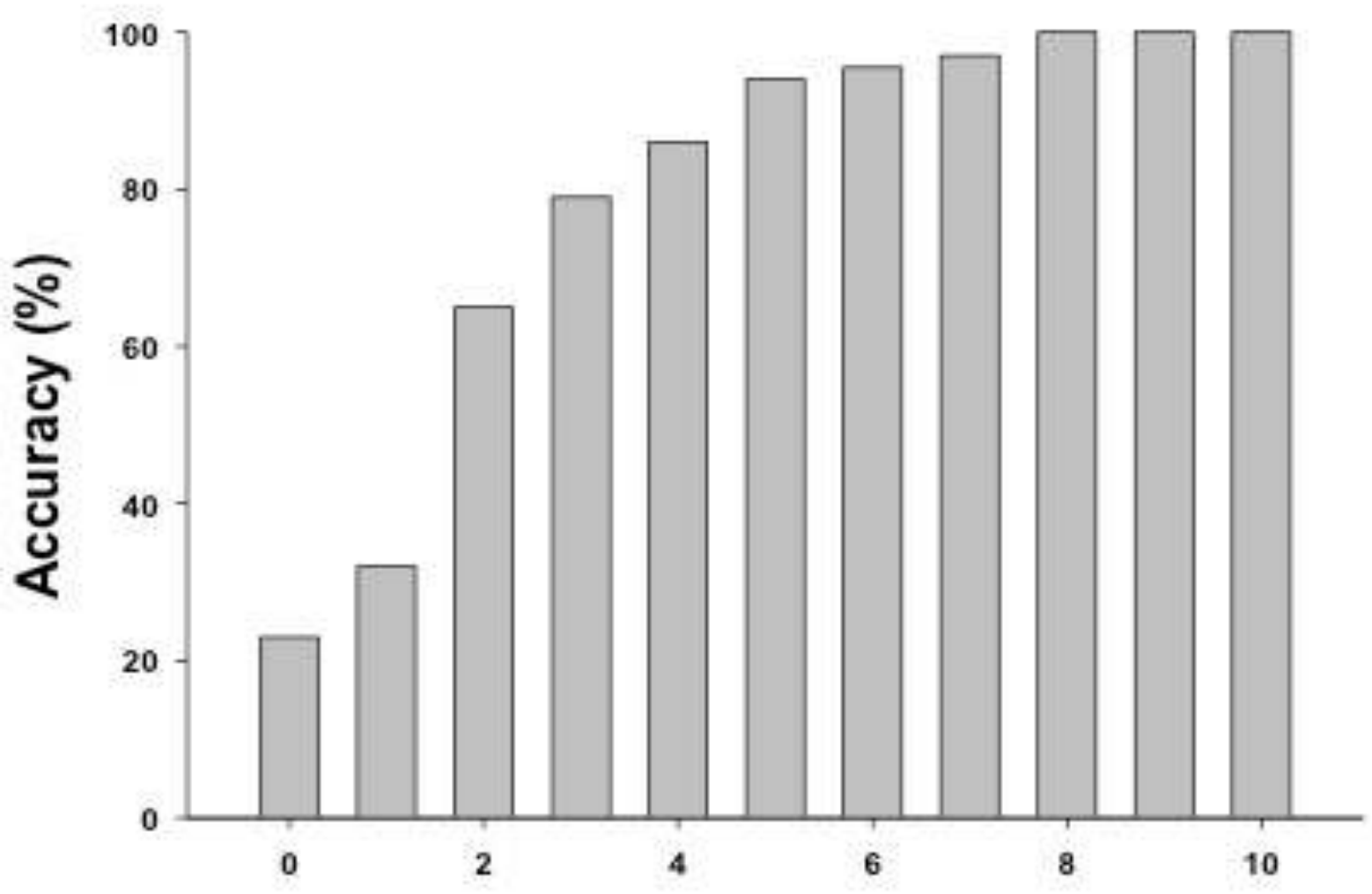

Hypothetical Incision Length 